\title{
EDITORIAL
}

\section{Suicide and second victims}

\section{A. Scott}

Consultant and Director, Department of Anaesthesia and Acute Pain Medicine, St Vincent's Hospital, and Professor, University of Melbourne, Victoria, Australia

Email: david.scott@svha.org.au

Keywords: suicide; survey; counselling; wellbeing

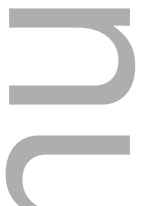

Accidental death or suicide is a tragic event, affecting many in addition to the victim. The sense of overwhelming despair that many survivors describe in the lead up an attempt at suicide may seem irrational or incomprehensible to those close to the victim. Likewise, when a highly stressed or depressed person ends up losing their life by dangerous exposure to potent drugs to try and escape their psychological pain, it seems similarly tragic. The circumstances surrounding the death of a family member, friend or colleague are complex and often pervaded with a sense of guilt, anger, or responsibility in some way by those who knew or interacted with the victim.

In our specialty of anaesthesia, we are exposed to a number of factors which contribute to accidental death or suicide. We undertake high stakes interventions on patients daily, which in many circumstances is neither fully appreciated nor valued by the public or even our peers who are not in the specialty. The rewards are great but relate mostly to personal satisfaction or recognition by colleagues. The stress that this places on us when things are challenging or go wrong, especially if we become isolated from support from our colleagues, or have fears of seeking help, adds to the stresses of normal life - relationships, income, health and so on[1]. We are also in a position where we also have access to some of the most powerful and dangerous drugs that are used in medicine, and the knowledge of what they do and how to use them [2, 3]. It is deeply unfortunate, but not

This is the author manuscript accepted for publication and has undergone full peer review but has not been through the copyediting, typesetting, pagination and proofreading process, which may lead to differences between this version and the Version of Record. Please cite this article as doi: 10.1111/ANAE.14763

This article is protected by copyright. All rights reserved 
surprising, that when the pressures get too great, we are often successful in taking our own lives, or in pushing the boundaries of pharmacological 'escape' too far and accidentally killing ourselves.

In this issue of Anaesthesia, Yentis et al. describe the results of a voluntary survey of anaesthetists who had practiced in the United Kingdom and identified a, perhaps surprisingly, high number of doctors who have been exposed during their career to the death of a colleague by suicide [4]. The nature of this survey means that there is likely a selection bias, in that those who have had an experience are more likely to respond. Likewise, the nature of our professional community and networks clearly means that one suicide is likely to affect a significant number of people. Nonetheless, 39\% of 3610 respondents had personal experience of at least one suicide. The quality of the data is supported by the number of respondents, and is consistent with other reports noting the high incidence of 'poisoning' reported as a means of suicide [3] although the reported sex ratio (males $3 \times$ females) varies in other studies from a similar rate of suicide in male and female doctors [5] to being higher in male doctors [3] . What can't gleaned from this survey is the actual incidence, which is reported to range from 14.8 to $19.2 / 100,000$ person-years for male doctors overall, nor that females are over-represented in doctors' suicide compared with the community [3], and that anaesthesia is a high-risk specialty for suicide [5].

The high numbers of anaesthetists experiencing a colleague's suicide needs to be heeded. The impact on family, friends and colleagues following a suicide or accidental death can be profound. In the healthcare system, those affected negatively by the impact of critical events are often referred to as 'second victims' [6]. It seems reasonable to apply this characterisation to those affected by the suicide or accidental death of a colleague. Following critical clinical incidents, anaesthetists have been shown to experience significant psychological distress [7], yet the significant negative psychological effects on colleagues of those who have died has not until recently been widely appreciated, nor has the extent of exposure to these events. In this current survey, the results could include events over many decades, but the relevance of the authors' findings are still sound. What is particularly unsettling is the way that these singularly tragic and impactful events have often (not) been managed in the workplace and a lack of awareness of supports or policies or even their presence.

What happens in the immediate aftermath is particularly critical. Support for those affected is essential, and everyone has different needs and concerns, including of course varying personal senses of guilt, anger or responsibility. There are, fortunately, some resources currently available to assist leaders in the workplace to acutely deal with an event such as suicide or accidental death of a colleague $[8,9]$, although these are not all anaesthesia-specific. As the survey results show 
respondents reported receiving little formal support and many more were unaware of the existence of formal policies or procedures to assist them [4]. Today in Australia and the UK, at least for individuals, most healthcare organisations have some form of Employee Assistance Program (EAP) whereby an individual employee can be placed in confidential contact with a (hopefully) experienced councillor who can guide them directly or who can direct them to more comprehensive support. Engagement with a GP or family doctor is encouraged as routine and provides another source of support and advice. The Australian and New Zealand College of Anaesthetists also provides a Doctors' Support Program to fellows and trainees (and their families) which includes options for face-to-face counselling and referral.

There is no 'perfect' way of managing such a challenging event, but what is needed more broadly, and identified in this survey, are tools to assist those leading their medical and nursing colleagues and other members of the peri-operative team in dealing with their sometimes complex emotions and concerns. As is highlighted in some useful resources [8], effective open and honest communication from early on is essential. While respecting the wishes of the family and relatives of the bereaved, it is important that everyone shares, as much as is possible, accurate knowledge of the same core elements of 'what is known about what happened'. To this end engagement with the family from early on is important if possible. Likewise, an appreciation is needed of the need in the workplace to accept that there are many ways that people respond to such an event - both acutely and in the long term.

Prevention is clearly an imperative. Doctors' health and wellbeing is an increasing focus of specialty organisations worldwide, including the Association of Anaesthetists, the Royal College of Anaesthetists, the College of Anaesthesiologists of Ireland and the Australian and New Zealand College of Anaesthetists. A number of strategies and resources have been developed by our professional organisations to help improve the quality of our work environment and the mental health of our trainees and specialist doctors throughout their careers. This includes peer support [1], mentoring resources, addressing triggers such as bullying, discrimination and sexual harassment, welfare advocates in training departments, and improved recommendations regarding factors such as fatigue in the workplace $[10,11]$, and post-crisis intervention[12]. Much more needs to be done for prevention, but in the meantime the impact on others should a suicide occur, as has been identified as being at a relatively high level by the results of this survey, can and should be managed much more effectively. The ongoing development of resources in this important area that are designed by our professional colleges and societies, for anaesthetists and anaesthesia workplaces, must be encouraged. 


\section{Acknowledgements}

DS is the Immediate Past President of the Australia and New Zealand College of Anaesthetists. No other conflicts of interest.

\section{References}

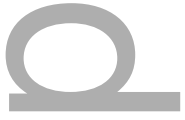

1. Vinson $A E$, Randel G. Peer support in anesthesia: turning war stories into wellness. Current Opinions in Anaesthesiology 2018; 31: 382-7.

2. Goldney RD Suicide by health care professionals. Medical Journal of Australia 2016; 205: 257-8.

3. Milner AJ, Maheen H, Bismark MM, Spittal MJ. Suicide by health professionals: a retrospective mortality study in Australia, 2001-2012. Medical Journal of Australia 2016; 205: 260-5.

4. Yentis S, Shinde S, Plunkett E, Mortimore A Suicide amongst anaesthetists - an Association of Anaesthetists survey. Anaesthesia 2019; TBC.

5. Hawton K, Clements A, Sakarovitch C, et al. Suicide in doctors: a study of risk according to gender, seniority and specialty in medical practitioners in England and Wales, 1979-1995. Journal of Epidemiology and Community Health 2001; 55: 296-300.

6. Wu AW. Medical error: the second victim. The doctor who makes the mistake needs help too. British Medical Journal 2000; 320: 726-7.

7. Gazoni FM, Amato PE, Malik ZM, Durieux ME. The impact of perioperative catastrophes on anesthesiologists: results of a national survey. Anesthesia and Analgesia 2012; 114: 596-603.

8. American Society of Suicidology, National Action Alliance for Suicide Prevention. A manager's guide to suicide prevention in the workplace: 10 action steps for dealing with the aftermath of suicide. 2013. https://www.sprc.org/resources-programs/managers-guidesuicide-postvention-workplace-10-action-steps-dealing-aftermath (accessed 10/06/2019).

9. Australia and New Zealand College of Anaesthetists. A manager's guideline for the sudden death of a colleague 2017. http://www.anzca.edu.au/documents/rd-27-managers-guidelinefor-sudden-dealth-of-coll.pdf (accessed 01/06/2019).

10. Association of Anaesthetists. Fatigue and Anaesthetists, 2014. https://anaesthetists.org/Home/Resources-publications/Guidelines/Fatigue-andAnaesthetists (accessed 01/06/2019). 
11. Australia and New Zealand College of Anaesthetists: PS43, Statement on fatigue and the anaesthetist 2019. http://www.anzca.edu.au/documents/ps43-2007-statement-on-fatigueand-the-anaesthetis.pdf (accessed 01//06/2019).

12. Australia and New Zealand College of Anaesthetist 2019.

http://www.anzca.edu.au/fellows/special-interest-groups/welfare-of-anaesthetists (accessed 01/06/2019).

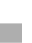
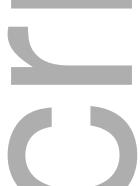

$\infty$

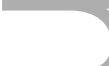

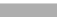
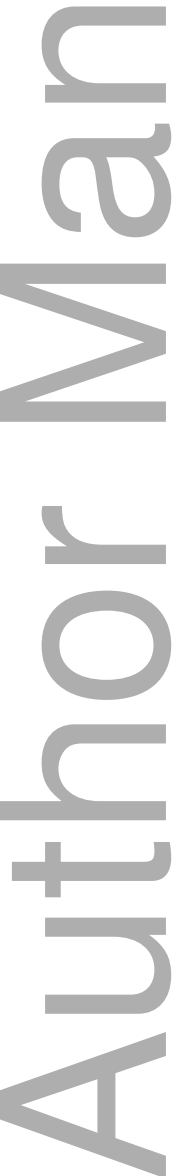

This article is protected by copyright. All rights reserved 


\section{University Library}

\section{- M M I E E R VA A gateway to Melbourne's research publications}

Minerva Access is the Institutional Repository of The University of Melbourne

Author/s:

Scott, DA

Title:

Suicide and second victims

Date:

2019-07-02

Citation:

Scott, D. A. (2019). Suicide and second victims. ANAESTHESIA, 74 (11), pp.1351-1353. https://doi.org/10.1111/anae.14763.

Persistent Link:

http://hdl.handle.net/11343/286078 